\title{
Dano econômico como critério na decisão sobre manejo de genótipos de arroz concorrentes em arroz irrigado
}

\author{
Dirceu Agostinetto ${ }^{(1)}$, Nilson Gilberto Fleck ${ }^{(1)}$, Mauro Antonio Rizzardi ${ }^{(1)}$ e Alvadi Antonio Balbinot Junior ${ }^{(1)}$
}

(1)Universidade Federal do Rio Grande do Sul, Fac. de Agronomia, Caixa Postal 15100, CEP 90001-970 Porto Alegre, RS.

E-mail: agostinetto@pucrs.campus2.br, fleck@ufrgs.br, rizzardi@zaz.com.br, babijr@ufrgs.br

\begin{abstract}
Resumo - Os níveis de dano econômico (NDE) em infestações de arroz daninho ou concorrente em lavouras de arroz cultivado permitem decidir o manejo na cultura e racionalizar o uso de herbicidas. O objetivo deste trabalho foi estimar NDE no arroz-vermelho e na cultivar de arroz EEA 406, usada como simuladora de arroz-vermelho, quando concorrem com arroz irrigado. Foram realizados três experimentos no campo, nas estações de crescimento 1999/2000 e 2000/2001. Avaliaram-se as populações dos genótipos competidores nos três experimentos e épocas relativas de emergência do arroz-vermelho (primeiro experimento), da cultivar simuladora (segundo experimento) e cultivares de arroz e espaçamentos entre linhas (terceiro experimento). Os NDE do arroz-vermelho foram inferiores aos da cultivar EEA 406. Os NDE estimados na cultivar EEA 406 variam amplamente, de acordo com as variáveis ambiente (ano), época de emergência, cultivar de arroz e espaçamento entre linhas da cultura. A emergência antecipada dos genótipos competidores em relação à cultura, o aumento do espaçamento entre linhas e a utilização de cultivares de ciclo curto diminuem os valores de níveis de dano econômico. Aumentos na produtividade de grãos, no preço de comercialização do arroz e na eficiência do controle e redução no custo do controle diminuem os NDE, tornando econômica a adoção de práticas de manejo sob menores populações dos genótipos competidores.
\end{abstract}

Termos para indexação: Oryza sativa, interferência, análise econômica, modelagem matemática.

\section{Economic threshold as a criterion for management decision of concurrent rice genotypes in flooded rice}

\begin{abstract}
The economic thresholds (ET) for weedy rice infestations in rice fields allow to decide the management of the rice crop, rationalizing herbicide use. The aim of this research was to estimate ET for red rice and for EEA 406 rice cultivar, mimicking red rice, when competing with flooded rice. Three field experiments were carried out, during the 1999/2000 and 2000/2001 growing seasons. The investigated factors were populations of the concurrents genotypes on the three experiments and red rice relative emergence times (first study), EEA 406 rice cultivar (second study) and rice cultivars and row widths (third experiment). ET values for red rice were lower than those for EEA 406 genotype. The ET values estimated for EEA 406 varied widely, according to environment (seasons), emergence time, rice cultivar and row width variables. Earlier emergence of concurrent genotypes in relation to the crop, increase in row width, and use of very early maturity cultivars decreased the ET values. Increases in grain yield, selling rice price and in control efficiency, and control cost reduction, decreased ET levels, making cost effective the adoption of management practices under lower concurrent genotype populations.

Index terms: Oryza sativa, interference, economic analysis, mathematical models.
\end{abstract}

\section{Introdução}

As culturas geneticamente modificadas ou mutantes resistentes aos herbicidas possibilitam controlar arrozvermelho (Oryza sativa L.) com aplicação de herbicidas antes não-seletivos em arroz cultivado. Porém, o preço do controle químico poderá representar um componente importante do custo de produção, afetando a lucratividade do produtor.
A aplicação de herbicidas ou de outros métodos de controle se justifica apenas quando o prejuízo causado por plantas competidoras supera o custo da medida utilizada. Numa lavoura infestada com elevada população de plantas daninhas, a decisão de controlá-las pode ser facilmente justificada, pois os agricultores estão cientes do efeito econômico negativo que populações elevadas causam às produtividades das culturas (Knezevic et al., 1997). Entretanto, em baixas populações de plantas dani- 
nhas, decisões de manejo tornam-se relativas, sendo necessário calcular o benefício econômico de controlálas, comparando-o ao custo do controle (Knezevic et al., 1997). Nesta situação, a decisão de implementar medidas de controle depende de se conhecer o resultado da interferência entre a cultura e as plantas daninhas (Beckett et al., 1988).

O grau de interferência de plantas daninhas em culturas pode variar sensivelmente, dependendo de fatores como população da cultura, época relativa de sua emergência, cultivar utilizada e práticas de manejo adotadas. Buscando modelar essas interações, diversos pesquisadores enfatizam estratégias de manejo que têm por base o conceito do nível de dano econômico (NDE) (Oliver, 1988; Onofri \& Tei, 1994; Van Devender et al., 1997). O NDE refere-se à população de plantas daninhas em que o ganho financeiro na produtividade da cultura, obtido pelo controle das plantas daninhas, iguala-se ao custo do controle adotado (Oliver, 1988; Bauer \& Mortensen, 1992; Coble \& Mortensen, 1992; Lindquist et al., 1996).

O nível de dano econômico foi introduzido como um conceito para racionalizar as decisões de controle de plantas daninhas, fazendo parte do programa de manejo integrado de plantas daninhas (McDonald \& Riha, 1999). Ao se usar o NDE como critério de decisão de controle, as reduções estimadas da produtividade de grãos são comparadas aos custos das opções de controle disponíveis, podendo-se então avaliar a lucratividade do tratamento de controle selecionado (Bauer \& Mortensen, 1992). Os NDE são variáveis e afetados por diversos fatores, tais como espécie daninha presente, nível populacional, época de emergência das plantas daninhas em relação à cultura, perda (porcentual) da produtividade da cultura, potencial de produtividade da cultura na ausência de plantas daninhas, preço de mercado do produto colhido, custos do controle, eficácia ou nível de controle atingido pelo tratamento e influência das plantas daninhas sobreviventes sobre o produto final (Oliver, 1988; Cardina et al., 1995; Knezevic et al., 1997).

O sucesso na decisão de aplicar medidas de controle apenas quando forem lucrativas depende da habilidade do produtor em determinar as populações de plantas daninhas, a partir das quais ocorrem os níveis de dano econômico. Também é fundamental que as relações de dano que quantificam as perdas na produtividade estejam disponíveis com base em observações da infestação de plantas daninhas no início do ciclo, sendo essas essenciais na avaliação da lucratividade das decisões para seu controle (Kropff \& Spitters, 1991).
O objetivo deste trabalho foi estimar NDE do arrozvermelho e da cultivar de arroz EEA 406, usada como simuladora de arroz-vermelho, quando concorrem com arroz irrigado.

\section{Material e Métodos}

Foram realizados três experimentos no campo, na Estação Experimental do Arroz, pertencente ao Instituto Rio-Grandense do Arroz (IRGA), no Município de Cachoeirinha, RS, nas estações de crescimento 1999/2000 e 2000/2001.

Nos três experimentos, o delineamento utilizado foi completamente casualizado, com tratamentos dispostos em esquema fatorial, com uma unidade experimental por combinação de fatores. No primeiro experimento, foi utilizado como concorrente o arroz-vermelho. No segundo e terceiro experimentos, utilizou-se como competidora a cultivar de arroz EEA 406, a qual, por apresentar características morfológicas semelhantes às do arroz-vermelho, exerceu a função de simuladora do arroz daninho. A não-utilização do próprio arroz-vermelho como infestante natural no segundo e terceiro experimentos deve-se ao nível elevado de dormência de suas sementes (Smith Junior, 1992; Agostinetto et al., 2001), o que leva à emergência desuniforme, dificultando o estabelecimento de populações predeterminadas no tempo e no espaço.

Nos dois primeiros experimentos realizados na estação de crescimento 1999/2000, o fator A comparou épocas de emergência dos genótipos competidores em relação à cultivar comercial $(-9,0$ e +8 dias $)$ e o fator $\mathrm{B}$ testou populações de arroz-vermelho (cinco níveis) no primeiro experimento e da cultivar simuladora (13 níveis) no segundo experimento. No terceiro experimento, realizado na estação de crescimento 2000/2001, o fator A avaliou cultivares de arroz (BRS-38 Ligeirinho, de ciclo muito curto; IRGA 417, de ciclo curto; e BRIRGA 409, de ciclo médio), o fator B contrastou espaçamentos entre linhas ( 15 e $25 \mathrm{~cm}$ ) e o fator C comparou populações da cultivar simuladora (10 níveis).

O preparo do solo foi realizado pelo sistema convencional de cultivo. Anteriormente à semeadura, realizouse adubação do solo de acordo com análise química. As unidades experimentais ocuparam áreas de $12 \mathrm{~m}^{2}$ nos três experimentos. Aplicaram-se, em cobertura, $90 \mathrm{~kg}$ de $\mathrm{N} \mathrm{ha}^{-1}$ (uréia) no primeiro e segundo experimentos e $80 \mathrm{~kg}$ de $\mathrm{N} \mathrm{ha}^{-1}$ no terceiro experimento. A uréia foi 
fracionada em três aplicações. O controle de plantas daninhas e insetos e as demais práticas de manejo foram realizadas conforme Embrapa Clima Temperado (1999).

As avaliações de populações de plantas dos genótipos competidores ocorreram aos 15 dias após a emergência da cultura (DAE), no primeiro e segundo experimentos e aos 14 DAE no terceiro experimento, e abrangeram contagens em duas áreas de $0,25 \mathrm{~m}^{2}$ por unidade experimental. Na determinação da produtividade de grãos do arroz irrigado, colheram-se as panículas na área central de cada unidade experimental, perfazendo 7,2 $\mathrm{m}^{2}$ nos dois primeiros experimentos e $4,2 \mathrm{~m}^{2}$ no terceiro experimento. Após a limpeza e pesagem dos grãos de arroz, procedeu-se a correção do teor de umidade para $13 \%$.

As perdas porcentuais de produtividade, em relação às unidades experimentais livres de plantas concorrentes, foram calculadas de acordo com a equação:

Perda $(\%)=\left(\frac{\mathrm{Ra}-\mathrm{Rb}}{\mathrm{Ra}}\right) \times 100$

em que Ra e Rb são as produtividades da cultura sem e com presença de plantas competidoras, respectivamente.

Ao modelo de regressão não-linear da hipérbole retangular (Cousens, 1985), ajustaram-se os dados de perdas de produtividade de acordo com a equação:

$$
\operatorname{Pr}=\frac{i X}{1+\left(\frac{i}{a}\right) X}
$$

em que Pr é a perda de produtividade (\%); X é a população, massa seca ou cobertura do solo, relativas aos competidores; i é a perda de produtividade (\%) por unidade dos genótipos competidores, quando a respectiva variável se aproxima de zero; a é a perda de produtividade (\%) quando a variável em questão tende ao infinito.

O ajuste dos dados ao modelo foi realizado pelo procedimento Proc Nlin do programa computacional SAS (SAS Institute, 1989). No processamento dos cálculos, utilizou-se o método de Gauss-Newton, o qual, por sucessivas iterações, estima os valores dos parâmetros do modelo nos quais seja mínima a soma dos quadrados dos desvios das observações, em relação aos valores ajustados (Ratkowsky, 1983).

No cálculo do nível de dano econômico (NDE), utilizaram-se as estimativas do parâmetro i obtidas a partir da Equação 2 (Cousens, 1985), e a equação adaptada de Lindquist \& Kropff (1996):
$\mathrm{NDE}=\frac{\mathrm{Cc}}{\operatorname{RP}\left(\frac{\mathrm{i}}{100}\right)\left(\frac{\mathrm{H}}{100}\right)}$

em que NDE é o nível de dano econômico (plantas $\mathrm{m}^{-2}$ ); Cc é o custo do controle (herbicida e aplicação, em dólares ha-1); R é a produtividade de grãos de arroz $\left(\mathrm{kg} \mathrm{ha}^{-1}\right)$; $\mathrm{P}$ é o preço do arroz (dólares $\mathrm{kg}^{-1}$ de grãos); i é a perda (\%) de produtividade do arroz por unidade de planta competidora, quando o nível populacional se aproxima de zero e H é o nível de eficiência do herbicida (\%).

Em relação às variáveis $\mathrm{Cc}, \mathrm{R}, \mathrm{P}$ e $\mathrm{H}$ (equação 3), foram estimados três valores, com base em dados médios dos últimos dez anos para a lavoura orizícola do Estado do Rio Grande do Sul (IRGA, 2002), ou obtidos nas recomendações para a cultura (Embrapa Clima Temperado, 1999). Assim, ao custo de controle (Cc) corresponderam valores de 45, 55 e 65 dólares ha ${ }^{-1}$; à produtividade de grãos (R), valores de 3.200, 5.200 e $7.200 \mathrm{~kg} \mathrm{ha}^{-1}$; ao preço do produto $(\mathrm{P})$, valores de 7,10 e 13 dólares por saca de $50 \mathrm{~kg}$ e, ao nível de eficiência herbicida $(\mathrm{H})$, valores de 80,90 e $100 \%$.

\section{Resultados e Discussão}

O conhecimento do potencial competitivo das plantas daninhas e da cultura são elementos básicos para prever a perda de produtividade. As estimativas obtidas para o parâmetro i foram 12,65, 4,07 e 1,67 no arroz-vermelho (primeiro experimento) e 4,81, 1,25 e 1,14 na cultivar simuladora (segundo experimento), respectivamente, quanto à primeira, segunda e terceira épocas de emergência (Tabela 1). Ao se admitir que o parâmetro i é um índice válido para comparar competitividades relativas entre espécies (Swinton et al., 1994), quanto menor for o valor estimado de i, menor é a habilidade competitiva do genótipo concorrente na associação. Deste modo, em ambos os genótipos competidores, a redução no valor estimado para o parâmetro i indica que, conforme o atraso da emergência relativa, há um decréscimo da mesma ordem no grau de competição do arroz cultivado.

Na comparação das habilidades dos genótipos competidores, as estimativas obtidas em relação ao parâmetro i, no caso do arroz-vermelho, primeiro experimento, indicam que sua presença causou maior impacto por interferência no arroz do que a da cultivar simuladora, segundo experimento. Ou seja, o arroz-vermelho demonstrou ser mais prejudicial à cultura do que a cultivar 
EEA 406, que pretendeu simular sua presença. Assim, o arroz-vermelho foi 2,6,3,3 e 1,5 vezes mais competitivo do que a cultivar EEA 406 na primeira, segunda e terceira época de emergência, respectivamente. Por sua vez, quando as plantas de arroz-vermelho emergiram nove dias antes da cultura, sua habilidade competitiva foi 3,1 vezes maior do que quando emergiram junto com a cultura, enquanto essa mesma comparação mostrou diferença de 3,9 vezes quanto à cultivar EEA 406. Isso vem demonstrar que a emergência antecipada de ervas em relação à cultura exerce efeito decisivo nas relações mútuas de interferência.

As plantas que primeiramente se estabelecem na área apresentam vantagens competitivas em relação àquelas que se estabelecem posteriormente (Paolini et al., 1998). O atraso na emergência da cultura, em relação às plantas daninhas, aumenta o nível de dano econômico (Cardina et al., 1995; Dieleman et al., 1996). A incorporação da época de emergência de caruru (Amaranthus spp.) no cálculo da função dano, quanto à cultura da soja, demonstrou que o atraso de 20 dias na emergência relativa da planta daninha aumentou em 19 vezes a população de plantas necessárias para se atingir nível de dano similar à emergência simultânea em ambas as espécies (Dieleman et al., 1996). De modo análogo, Rizzardi et al. (2003) constatou que o atraso na semeadura da soja, em relação à dessecação da cobertura vegetal, afetou consideravelmente o grau de interferência de Bidens spp. e Sida rhombifolia L. com a cultura.

No primeiro experimento, a antecipação de nove dias na emergência do arroz-vermelho, em relação ao cultivado, reduziu os NDE em todas as simulações realizadas, cujas variações foram de 0,3 a 6 plantas $\mathrm{m}^{-2}$ (Figura 1). Já as estimativas do NDE, no caso da cultivar EEA 406, simuladora de arroz-vermelho (segundo experimento), mostram níveis maiores, com variações entre 0,9 e 8 plantas $\mathrm{m}^{-2}$ (Figura 2). De modo semelhante ao verificado em relação ao arroz-vermelho, a antecipação da emergência da cultivar simuladora reduziu os valores de NDE em todas as simulações realizadas. No entanto, tendo por base a média das três épocas de emergência da simuladora e o valor intermediário da variável produtividade de grãos, verifica-se ser possível tolerar aproximadamente o dobro de plantas da cultivar simuladora quanto ao NDE, em relação ao do arrozvermelho.

Ao se fixar as médias das três épocas de emergência estudadas, a comparação entre a menor produtividade de grãos - valor aproximado da produtividade média nacional - e a maior produtividade - valor obtido em lavouras que adotam alto nível tecnológico no Estado do

Tabela 1. Perda da produtividade de grãos de arroz irrigado em função de época de emergência, cultivar e espaçamento entre linhas e de população (X) do arroz-vermelho ou da cultivar EEA 406, simuladora de arroz-vermelho. IRGA/Cachoeirinha, RS, 1999/2000-2000/2001.

\begin{tabular}{|c|c|c|c|}
\hline Competidor & Época de emergência ${ }^{(1)}$ & Perda de produtividade $(\%)^{(2)}$ & $\mathrm{R}^{2}$ \\
\hline \multirow{4}{*}{ Arroz-vermelho } & & Primeiro experimento & \\
\hline & Nove dias antes & $(12,65 X) /(1+((12,65 / 100) X))$ & 0,92 \\
\hline & No mesmo dia & $(4,07 \mathrm{X}) /(1+((4,07 / 100) \mathrm{X}))$ & 0,65 \\
\hline & Oito dias após & $(1,67 \mathrm{X}) /(1+((1,67 / 100) \mathrm{X}))$ & 0,91 \\
\hline \multirow{4}{*}{$\begin{array}{l}\text { Cultivar } \\
\text { EEA } 406\end{array}$} & & Segundo experimento & \\
\hline & Nove dias antes & $(4,81 X) /(1+((4,81 / 100) X))$ & 0,75 \\
\hline & No mesmo dia & $(1,25 X) /(1+((1,25 / 100) X))$ & 0,78 \\
\hline & Oito dias após & $(1,14 X) /(1+((1,14 / 25) X))$ & 0,47 \\
\hline \multirow{8}{*}{$\begin{array}{l}\text { Cultivar } \\
\text { EEA } 406\end{array}$} & Cultivar/ espaçamento & Perda de produtividade $(\%)^{(2)}$ & $\mathrm{R}^{2}$ \\
\hline & & Terceiro experimento & \\
\hline & BRS-38 / $15 \mathrm{~cm}$ & $(0,63 X) /(1+((0,63 / 100) X))$ & 0,64 \\
\hline & BRS-38 / $25 \mathrm{~cm}$ & $(0,70 \mathrm{X}) /(1+((0,70 / 100) \mathrm{X}))$ & 0,75 \\
\hline & IRGA $417 / 15 \mathrm{~cm}$ & $(0,25 X) /(1+((0,25 / 100) X))$ & 0,68 \\
\hline & IRGA $417 / 25 \mathrm{~cm}$ & $(0,51 \mathrm{X}) /(1+((0,51 / 92) \mathrm{X}))$ & 0,85 \\
\hline & BR-IRGA $409 / 15 \mathrm{~cm}$ & $(0,32 \mathrm{X}) /(1+((0,32 / 82) \mathrm{X}))$ & 0,85 \\
\hline & BR-IRGA 409 / $25 \mathrm{~cm}$ & $(0,77 \mathrm{X}) /(1+((0,77 / 100) \mathrm{X}))$ & 0,87 \\
\hline
\end{tabular}

${ }^{(1)}$ Em relação à época de emergência do arroz cultivado. ${ }^{(2)}$ Estimada pelo modelo de regressão da hipérbole retangular (Cousens, 1985). 

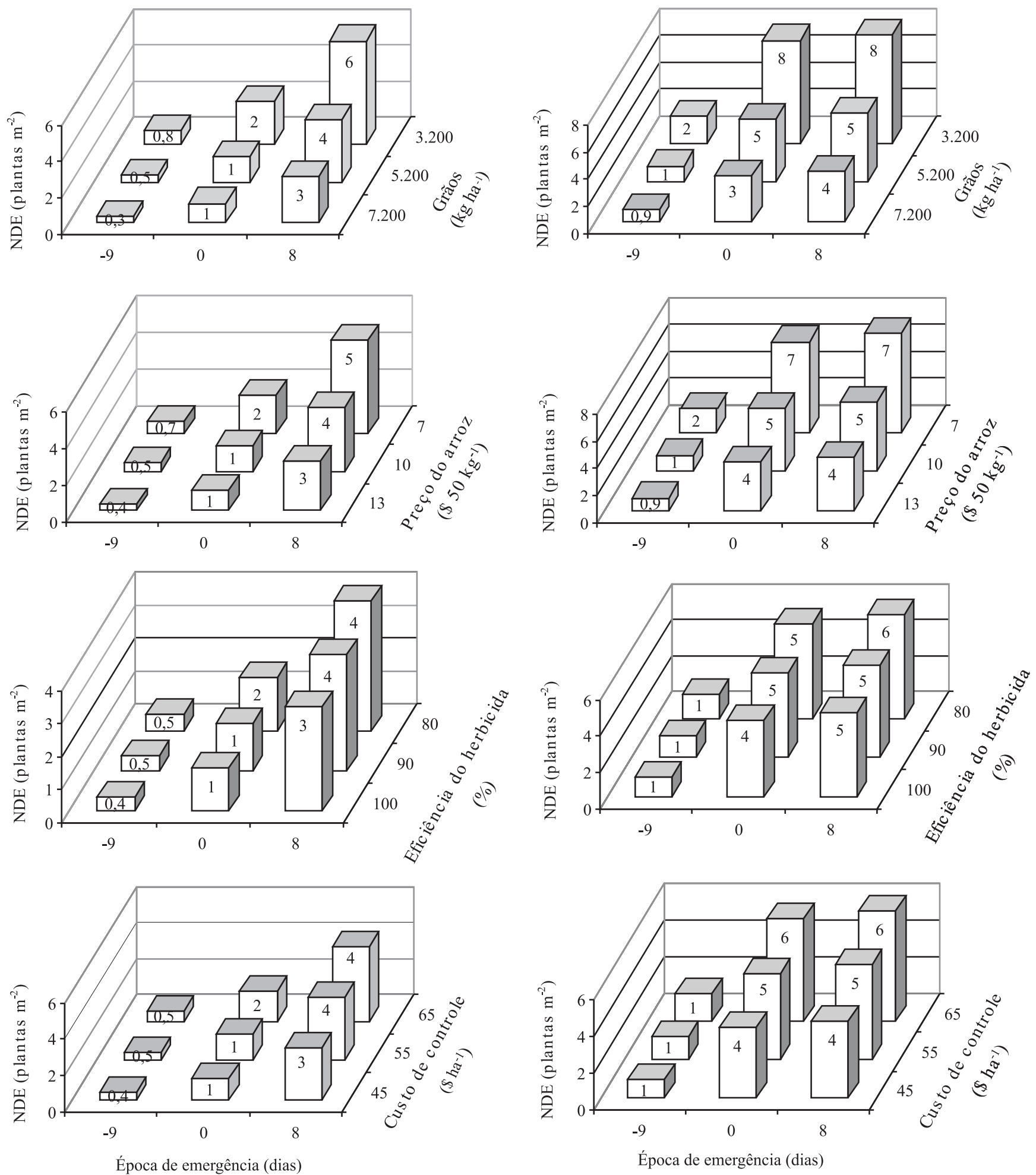

Figura 1. Nível de dano econômico (NDE) para arroz irrigado, cultivar IRGA 417, em função de população e época relativa de emergência de arroz-vermelho em relação ao arroz cultivado. IRGA/Cachoeirinha, RS, 1999/2000.

Figura 2. Nível de dano econômico (NDE) para arroz irrigado, cultivar IRGA 417, em função de população e época relativa de emergência da cultivar EEA 406, simuladora de arroz-vermelho, em relação ao arroz cultivado. IRGA/Cachoeirinha, RS, 1999/2000. 
Rio Grande do Sul -, verificam-se diferenças nos NDE da ordem de $105 \%$ e $128 \%$ para arroz-vermelho e cultivar simuladora, respectivamente (Figuras 1 e 2). Deste modo, quanto maior for o potencial de produtividade da cultura, menor será a população de plantas concorrentes necessária para superar o NDE, tornando potencialmente mais econômica a adoção de medidas de controle.

No terceiro experimento, os valores estimados para o parâmetro i variaram de 0,25 a 0,77 (Tabela 1 ). Os menores valores de i foram obtidos no menor espaçamento entre linhas, indicando que a redução desta variável diminui a habilidade competitiva das plantas concorrentes ou aumenta a da cultura. A redução no espaçamento entre linhas diminuiu os valores estimados para o parâmetro i em 10\%, 51\% e 58\% nos cultivares BRS-38 Ligeirinho, IRGA 417 e BR-IRGA 409, respectivamente. A menor diferença dos valores de i entre espaçamentos, verificada na cultivar BRS-38 Ligeirinho, demonstra que nesta cultivar a redução da variável não alterou consideravelmente o nível de competição com a cultivar concorrente. Entre cultivares, em média, os maiores valores estimados do parâmetro i corresponderam à cultivar BRS-38 Ligeirinho, indicando ser essa cultivar menos competitiva com a cultivar simuladora do que as outras duas. Esses resultados podem ser decorrentes do ciclo da cultivar e de suas características morfofisiológicas, já que cultivares de ciclo muito curto apresentam menor fase vegetativa e, conseqüentemente, há menor período no acúmulo de fotoassimilados para investir em estruturas da planta.

A redução no espaçamento entre linhas, associada à população adequada de plantas, pode aumentar consideravelmente a habilidade competitiva da cultura com plantas concorrentes e o próprio potencial de produtividade do cultivo. Isso decorre da melhor utilização de recursos do ambiente pela cultura, em detrimento de seu uso por plantas daninhas. Neste sentido, Menezes \& Silva (1998) constataram que a produtividade de grãos das cultivares de arroz BR-IRGA 410 e IRGA 416, em presença de arroz-vermelho, foi menos afetada pela competição no espaçamento entre linhas de $13,5 \mathrm{~cm}$, comparativamente aos espaçamentos de 20 e $30 \mathrm{~cm}$, na densidade de semeadura de $150 \mathrm{~kg} \mathrm{ha}^{-1}$. Segundo esses autores, os resultados se devem ao aumento da capacidade de competição do arroz cultivado sobre o arroz-vermelho, na medida em que diminuiu a competição intra-específica e aumentou a competição interespecífica pelo melhor arranjo de plantas da cultura.
No terceiro experimento, as estimativas obtidas do NDE variaram de 6 a 15; 8 a 38 e 6 a 30 plantas $m^{-2}$, considerando-se, respectivamente, espaçamentos entre linhas de 25 e $15 \mathrm{~cm}$ e as cultivares BRS-38 Ligeirinho, IRGA 417 e BR-IRGA 409 (Figura 3). Nas três cultivares testadas, observou-se redução nos valores de NDE com o aumento do espaçamento entre linhas em todas as simulações realizadas. Ainda, tomando por base a média da produtividade de grãos de arroz no Estado $\left(5.200 \mathrm{~kg} \mathrm{ha}^{-1}\right)$ e o espaçamento entre linhas de $15 \mathrm{~cm}$, próximo ao comumente utilizado pelos orizicultores, verifica-se que a cultivar IRGA 417 apresentou NDE superior ao das cultivares BRS-38 Ligeirinho e BRIRGA 409 , da ordem de $167 \%$ e $33 \%$, respectivamente, o que a posiciona como mais competitiva.

A ordem decrescente dos valores de NDE, levandose em conta cultivar e espaçamento entre linhas, e tendo por base os valores médios das estimativas de NDE, foi IRGA $417(15 \mathrm{~cm})>$ BR-IRGA $409(15 \mathrm{~cm})>$ IRGA $417(25 \mathrm{~cm})>$ BRS-38 Ligeirinho $(15 \mathrm{~cm})>$ BRS-38 Ligeirinho $(25 \mathrm{~cm})>$ BR-IRGA $409(25 \mathrm{~cm})$. Os maiores NDE obtidos para as cultivares IRGA 417 e BR-IRGA 409, no menor espaçamento, podem estar relacionados ao seu maior ciclo de desenvolvimento. Neste aspecto, Menezes \& Silva (1998) relatam que o maior ciclo da cultivar de arroz BR-IRGA 410 proporcionou-lhe vantagem competitiva em relação à cultivar IRGA 416, quando em competição com arroz-vermelho.

Em todas as simulações realizadas, independentemente dos fatores testados, aumentos no potencial de produtividade de grãos da cultura, no preço do produto colhido ou na eficiência do herbicida diminuíram os níveis de dano economômico. Desse modo, em lavouras nas quais as estimativas do potencial de produtividade forem elevadas, uma menor população de plantas concorrentes justifica economicamente a aplicação de herbicida. Por sua vez, o incremento no custo de controle aumentou os NDE, demonstrando que a adoção de medida de controle somente se justifica economicamente quando as infestações de plantas daninhas forem mais elevadas.

Analisando-se conjuntamente os três experimentos e tomando-se os valores intermediários das faixas de cada variável, constata-se que o peso de cada uma sobre o nível de dano econômico mostra a seguinte ordem decrescente de grandeza: produtividade de grãos $>$ preço do arroz > custo de controle > eficiência herbicida. Isso demonstra que o potencial de produtividade da cultura representa a principal variável na delimitação do valor do nível de dano econômico. 

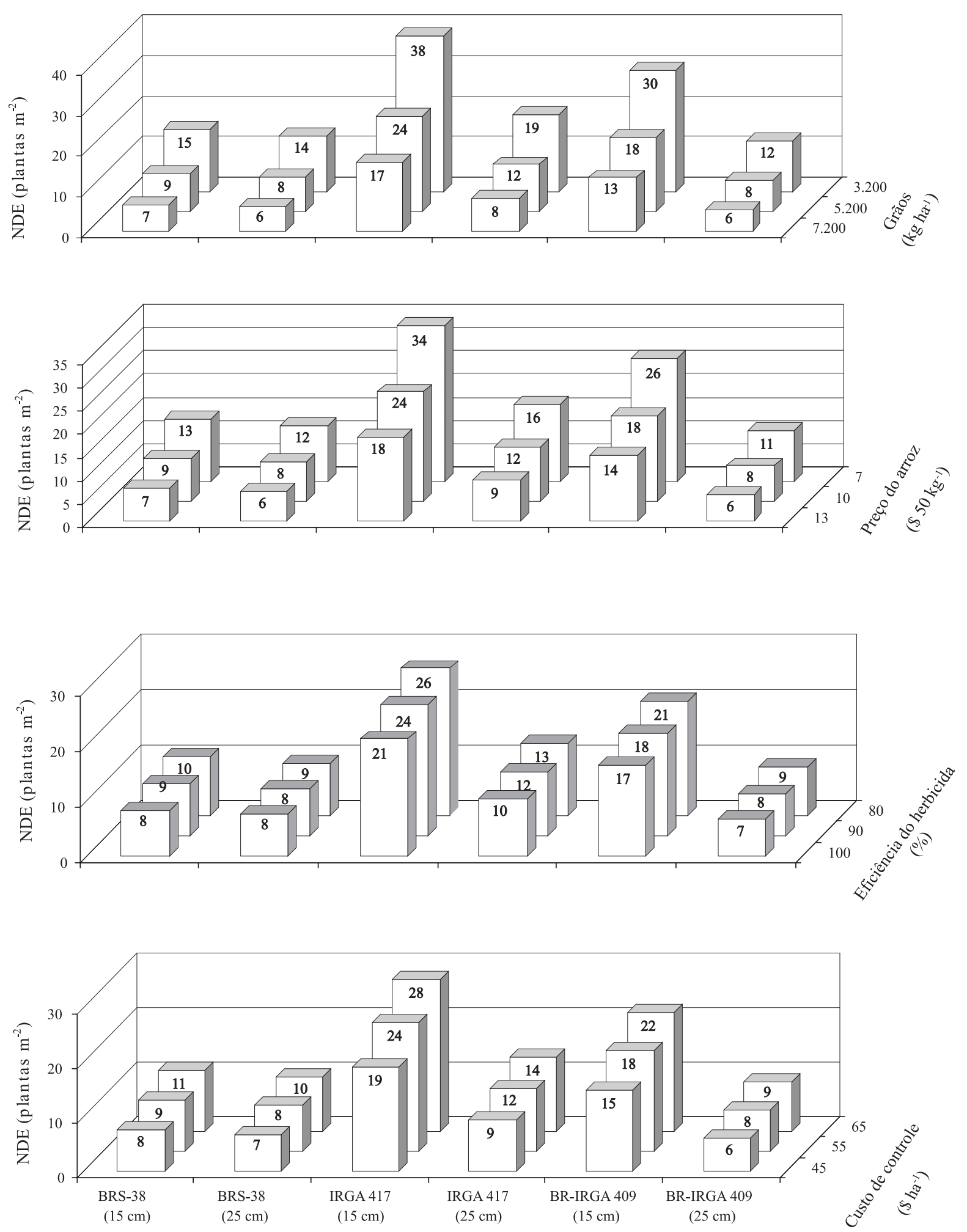

Cultivar de arroz e espaçamento entre linhas

Figura 3. Nível de dano econômico (NDE) em arroz irrigado em função de cultivar e espaçamento entre linhas e população da cultivar EEA 406, simuladora de arroz-vermelho. IRGA/Cachoeirinha, RS, 2000/01. 
D. Agostinetto et al.

A aplicação prática do conceito de NDE em decisões de controle de plantas daninhas em pós-emergência, baseadas em uma única safra, sofre limitação de alguns fatores como dificuldade em desenvolver métodos simples e baratos para quantificar os efeitos da interferência de plantas daninhas sobre a cultura, ocorrência de multiespécies na maioria das lavouras e, principalmente, o impacto de fatores do ambiente na interação cultura-plantas daninhas em diferentes locais e anos (Kropff \& Sppiters, 1991; Swinton et al., 1994).

Os NDE foram calculados com base em uma única safra e não incluem o fator associado ao possível aumento do banco de sementes no solo nos anos seguintes. Muitas críticas atribuídas ao conceito de níveis de dano no manejo de plantas daninhas com base em uma única estação de crescimento referem-se ao custo associado à adição de sementes de plantas daninhas ao banco de sementes pelas populações não controladas que se situam abaixo do NDE nas safras subseqüentes (Norris, 1992). A inclusão do fator produção de sementes ao conceito pode reduzir significativamente os NDE, aumentando a necessidade de adoção de medidas de controle (Coble \& Mortensen, 1992). Diversas pesquisas sugerem a diminuição do NDE para um nível de dano econômico ótimo (NDEO) quando também for considerada a produção de sementes (Bauer \& Mortensen, 1992; Rizzardi et al., 2003).

Quando se consideram as implicações agronômicas decorrentes de características ecofisiológicas do arrozvermelho durante um período de tempo mais longo, é provável que o uso do NDE de uma única safra, como critério de decisão, não seja a melhor estratégia para seu manejo. Nesta situação, é prudente que o orizicultor use a abordagem de NDEO, prevenindo assim a formação de banco de sementes, pois características como dormência e longevidade das sementes poderão assegurar a presença do arroz-vermelho durante muitos anos no local.

\section{Conclusões}

1. Os níveis de dano econômico no arroz-vermelho são inferiores aos da cultivar EEA 406, usada como simuladora do arroz-vermelho, quando concorrem com a cultivar de arroz IRGA 417.

2. Os níveis de dano econômico estimados para a cultivar EEA 406, como simuladora de arroz-vermelho, variam amplamente, em função do ambiente (ano), da cultivar de arroz e das práticas de manejo adotadas para a cultura.

3. A emergência antecipada dos genótipos competidores em relação à cultura, o aumento do espaçamento entre linhas do arroz e a utilização de cultivares de ciclo muito curto diminuem os valores de nível de dano econômico.

4. Aumentos na produtividade de grãos, no preço do arroz e na eficiência do herbicida e a redução no custo do controle diminuem os valores de nível de dano, justificando economicamente a adoção de práticas de controle ou de adubação sob menores populações de arrozvermelho.

\section{Agradecimento}

Ao CNPq, pela bolsa concedida ao autor Nilson Gilberto Fleck.

\section{Referências}

AGOSTINETTO, D.; FLECK, N.G.; RIZZARDI, M.A.; VIDAL, R.A.; MEROTTO JUNIOR, A. Arroz-vermelho: ecofisiologia e manejo. Ciência Rural, v.31, p.341-349, 2001.

BAUER, T.A.; MORTENSEN, D.A. A comparison of economic and economic optimum thresholds for two annual weeds in soybeans. Weed Technology, v.6, p.228-235, 1992.

BECKETT, T.H.; STOLLER, E.W.; WAX, L.M. Interference of four annual weeds in corn (Zea mays). Weed Science, v.36, p.764769, 1988.

CARDINA, J.; REGNIER, E.; SPARROW, D. Velvetleaf (Abutilon theophrasti) competition and economic thresholds in conventional and no-tillage corn (Zea mays). Weed Science, v.43, p.81-87, 1995.

COBLE, H.D.; MORTENSEN, D.A. The threshold concept and its application to Weed Science. Weed Technology, v.6, p.191-195, 1992.

COUSENS, R. An empirical model relating crop yield to weed and crop density and a statistical comparison with other models. Journal of Agricultural Science, v.105, p.513-521, 1985.

DIELEMAN, A.; HAMILL, A.S.; FOX, G.C.; SWANTON, C.J. Decision rules for postemergence control of pigweed (Amaranthus spp.) in soybean (Glycine max). Weed Science, v.44, p.126-132, 1996.

EMBRAPA CLIMA TEMPERADO. Arroz irrigado: recomendações técnicas da pesquisa para o Sul do Brasil. Pelotas: Embrapa Clima Temperado; Irga; Epagri, 1999. 124p. (Documento, 57).

IRGA. Arroz irrigado no RS: área, produção e rendimento. Disponível em: <http://www.irga.rs.gov.br> Acesso em 5 out. 2002.

KNEZEVIC, S.Z.; HORAK, M.J.; VANDERLIP, R.L. Relative time of redroot pigweed (Amaranthus retroflexus $\mathrm{L}$.) emergence is critical 
in pigweed-sorghum [Sorghum bicolor (L.) Moench] competition. Weed Science, v.45, p.502-508, 1997.

KROPFF, M.J.; SPITTERS, C.J.T. A simple model of crop loss by weed competition from early observations on relative leaf area of weeds. Weed Research, v.31, p.97-105, 1991.

LINDQUIST, J.L.; KROPFF, M.J. Applications of an ecophysiological model for irrigated rice (Oryza sativa) - Echinochloa competition. Weed Science, v.44, p.52-56, 1996.

LINDQUIST, J.L.; MORTENSEN, D.A.; CLAY, S.A.; SCHMENK, R.; KELLS, J.J.; HOWATT, K.; WESTRA, P. Stability of corn (Zea mays) velvetleaf (Abutilon theophrasti) interference relationships. Weed Science, v.44, p.309-313, 1996.

McDONALD, A.J.; RIHA, S.J. Model of crop:weed competition applied to maize: Abutilon theophrasti interactions: II. Assessing the impact of climate: implications for economic thresholds. Weed Research, v.39, p.371-381, 1999.

MENEZES, V.G.; SILVA, P.R.F. da. Manejo de arroz-vermelho através do tipo e arranjo de plantas em arroz irrigado. Planta Daninha, v.16, p.45-58, 1998.

NORRIS, R.F. Case history for weed competition/population ecology: barnyardgrass (Echinochloa crus-galli) in sugarbeets (Beta vulgaris). Weed Technology, v.6, p.220-227, 1992.

OLIVER, L.R. Principles of weed threshold research. Weed Technology, v.2, p.398-403, 1988.
ONOFRI, A.; TEI, F. Competitive ability and threshold levels of three broadleaf weed species in sunflower. Weed Research, v.34, p.471-479, 1994.

PAOLINI, R.; DEL PUGLIA, S.; PRINCIPI, M.; BARCELLONA, O.; RICCARDI, E. Competition between safflower and weeds as influenced by crop genotype and sowing time. Weed Research, v.38, p.247-255, 1998.

RATKOWSKY, D.A. Nonlinear regression modeling: a unified practical approach. New York: Marcel Dekker, 1983. p.135-154.

RIZZARDI, M.A.; FLECK, N.G.; RIBOLDI, J.; AGOSTINETTO, D. Ajuste de modelo para quantificar o efeito de plantas daninhas e época de semeadura no rendimento de soja. Pesquisa Agropecuária Brasileira, v.38, p.35-43, 2003.

SAS INSTITUTE (Cary, Estados Unidos). User's guide: version 6.4. Cary, 1989. 846p.

SMITH JUNIOR, R.J. Red rice control. Agribusiness Worldwide, Sept./Oct., p.18-23, 1992.

SWINTON, S.M.; BUHLER, D.D.; FORCELLA, F.; GUNSOLUS, J.L.; KING, R.P. Estimation of crop yield loss due to interference by multiple weed species. Weed Science, v.42, p.103-109, 1994.

VAN DEVENDER, K.W.; COSTELLO, T.A.; SMITH JUNIOR, R.J. Model of rice (Oryza sativa) yield reduction as a function of weed interference. Weed Science, v.45, p.218-224, 1997.

$\overline{\text { Recebido em } 13 \text { de outubro de } 2003 \text { e aprovado em } 14 \text { de dezembro de } 2004}$ 